\title{
EVOLUTION OF ANTHOCYANINS DURING VINIFICATION OF MERLOT AND PINOT NOIR GRAPES TO WINES
}

\author{
M. Dimitrovska ${ }^{\text {a* }}$, M. Bocevska ${ }^{\mathrm{b}}$, D. Dimitrovski $^{\mathrm{b}}$ and D. Doneva-Sapceska ${ }^{\mathrm{b}}$ \\ ${ }^{a}$ Institute of Public Health, 50 Divizija 6, 1000 Skopje. Macedonia \\ ${ }^{\mathrm{b}}$ Department of Food Technology and Biotechnology, Faculty of Technology and Metallurgy, Ss. Cyril and \\ Methodius University, Rudjer Boskovic 16, 1000 Skopje. Macedonia
}

(Received: 17 October 2013; accepted: 6 March 2014)

\begin{abstract}
The evolution of individual anthocyanins during vinification of Merlot and Pinot Noir grapes was studied using two different winemaking procedures for each grape variety. Additionally, the effect of the applied vinification on the anthocyanin composition of the obtained wine at the end of maceration and wine aged 6 months was investigated and compared with the anthocyanin patterns of the original grape. The dynamics of the extraction process was monitored daily during maceration by analysing the anthocyanins in the must using HPLC. The results showed that the anthocyanin composition of young wines was different from that of the grapes. The proportions of malvidin-3glucoside and malvidin-acetate were higher in wines than in the grape skins, but this was not the case for malvidin coumarate. Application of different vinification procedures to the same raw material resulted in wines with similar anthocyanin patterns. However, the anthocyanin profiles changed with the ageing of the wines.
\end{abstract}

Keywords: wine, anthocyanins, vinification, fingerprint, Merlot, Pinot Noir

The colour properties and appearance of red wines are directly influenced by their constituents, primarily anthocyanins. These flavonoid compounds are accumulated in the skins of grape berries during maturation. Later, during maceration, in the process of winemaking they are extracted into the must (BAUTISTA-Ortín et al., 2007). Since their synthesis in grape is related to genetic factors, anthocyanins are considered as chemical markers for differentiation of the grape varieties (AROZARENA et al., 2000). Some studies provide data on the possibility of using the anthocyanin pattern of the wine in certification of the authenticity of single variety wines (García-Beneytez et al., 2002; Casavecchia et al., 2007). However, there are assumptions that some changes of the anthocyanin pattern occur during the alcoholic fermentation as a result of the different rate of extraction of the anthocyanins, their degradation, polymerisation, or adsorption to the yeast cell walls (REviLla et al., 2001; Romero-CASCALES et al., 2005). Numerous factors may affect the extraction of the anthocyanins in the must. For example, prolonged maceration treatments are usually related to higher content of anthocyanins in wine (GómEz-PlazA et al., 2002). Also, application of various enzyme preparations in the process of maceration is a reason for significant differences in the concentration of the identified anthocyanins in wines (KELEBEK et al., 2007).

The aim of this work was to investigate the influence of the winemaking process, in particular the addition of oenological aids and additives, on the anthocyanin composition and concentration in wines. For that reason, two vinification protocols were performed with each of the studied grape varieties, Merlot and Pinot Noir. The rate of extraction of anthocyanins

\footnotetext{
* To whom correspondence should be addressed.

Phone: +389-71-317 440; fax: +389-2-3223 354; e-mail: m.dimitrovska@iph.mk
}

0139-3006/\$20.00 @ 2015 Akadémiai Kiadó, Budapest 
from skins to must was monitored during the maceration period. The anthocyanin patterns of the grape skins and corresponding wines were compared for each of the studied grape varieties to evaluate how the anthocyanin pattern is affected by the vinification.

\section{Materials and methods}

\subsection{Grape samples}

Grapes (Vitis vinifera L.) from two different cultivars, Merlot (sugars $219.1 \mathrm{~g} \mathrm{~kg}^{-1}$, titratable acidity $5.16 \mathrm{~g} \mathrm{l}^{-1}$ tartaric acid, $\mathrm{pH} 3.59$ ) and Pinot Noir (sugars $178.4 \mathrm{~g} \mathrm{~kg}^{-1}$, titratable acidity $5.81 \mathrm{~g} \mathrm{l}^{-1}$ tartaric acid, $\mathrm{pH}$ 3.38) cultivated in Tikves, Povardarie wine region (R. Macedonia) were harvested from commercial vineyards in September 2008 at optimal maturity.

\subsection{Wine samples}

Grapes of Merlot and Pinot Noir varieties were vinified at industrial scale following two different winemaking procedures for each variety. Merlot was processed in order to obtain fully bodied, structured wine, intended for aging (fermentation M-1) and to produce fruity and aromatic wine intended for early bottling (fermentation M-2). Two other fermentation procedures were conducted for Pinot Noir grapes, fermentation PN-1 and fermentation PN-2. For all fermentations, grapes were destemmed and crushed, transferred to stainless steel tanks (1000 1), and potassium metabisulfite was immediately added to the must to obtain an $\mathrm{SO}_{2}$ concentration of $30 \mathrm{mg} \mathrm{l}^{-1}$.

Fermentation M-1 was conducted using commercial pectolytic preparation (Lallzyme EX-V, Lallemand Inc., Canada, $1.5 \mathrm{~g} / 100 \mathrm{~kg}$ grapes) followed by addition of toasted oak chips (Boisé France, $0.5 \mathrm{~kg} \mathrm{t}^{-1}$ ) on the first day of fermentation. After 2 days maceration $\left(21^{\circ} \mathrm{C}\right)$, dry active yeast (Lalvin ICV-D254, Lallemand Inc., Canada, $25 \mathrm{~g} \mathrm{hl}^{-1}$ ) was introduced to the tank. Polygalacturonase (Vinozyme Vintage FCE, Novozymes AG, Dittingen, Switzerland, $5 \mathrm{~g} / 100 \mathrm{~kg}$ grapes) was used as a macerating enzyme for fermentation M-2 and the must was inoculated with commercial yeast (L.A. N ${ }^{\circ}$, Lamothe-Abiet, Bordeaux, France, $25 \mathrm{~g} \mathrm{hl}^{-1}$ ). On the third day of fermentation, oenological tannin (Pro Tanin, LamotheAbiet, Bordeaux, France, $20 \mathrm{~g} \mathrm{hl}^{-1}$ ) and enzyme with pectinase/beta-glucanase activity (Vinoflow FCE, Novozymes AG, Dittingen, Switzerland, $5 \mathrm{~g} \mathrm{hl}^{-1}$ ) were supplied.

As for fermentation PN-1, enzyme with pectolytic activity (Lallzyme OE, Lallemand Inc., Canada, $1 \mathrm{~g} / 100 \mathrm{~kg}$ grapes) was added immediately after crushing the grapes and untoasted oak chips (Boisé France, $75 \mathrm{~g} \mathrm{hl}^{-1}$ ) were supplied to the must. Commercial yeast (Lalvin Rhône L2056, Lallemand Inc., Canada, $17 \mathrm{~g} \mathrm{hl}^{-1}$ ) was introduced after two days. Fermentation PN-2 was carried out under the same conditions as fermentation PN-1, but without addition of oak chips.

Maceration in all fermentations was carried out by pumping-over twice a day and fermentation temperature was controlled between 24 and $29^{\circ} \mathrm{C}$ for Merlot and 17 and $23{ }^{\circ} \mathrm{C}$ for Pinot Noir. After completion of the alcoholic fermentation, the wines were devatted and separated from the marc and transferred to other containers, where malolactic fermentation occurred. At the end, the wines were separated from the coarse lees, the level of $\mathrm{SO}_{2}$ was corrected $\left(40 \mathrm{mg} \mathrm{l}^{-1}\right)$, and were racked once a month until the last sampling.

Samples were taken daily during the maceration period. Then, the young wines were analysed six months after the elaboration. 


\subsection{Reagents and standards}

For the HPLC determination of the anthocyanins, acetonitrile (gradient grade) was used, purchased from Merck (Darmstadt, Germany). Hydrochloric acid, formic acid and methanol of analytical reagent grade were purchased from Sigma-Aldrich (St. Lois, Missouri, USA). Oenin chloride obtained from Extrasynthese (GenayCedex, France) was used as external standard for quantification. Ultrapure water for analysis was produced by system TKA Lab micro (Niederelbert, Germany).

\subsection{Extraction of anthocyanins from grape skins}

In order to determine the anthocyanins in the fresh grape skins of the studied grape cultivars, a procedure of extraction was carried out within one day of the harvest. Several berries were picked from each collected grape bunch, making a pooled sample of 150-200 g. After manually peeling the skins of the grape berries, the anthocyanins were extracted using aqueous solution of methanol $(60 \%, \mathrm{v} / \mathrm{v})$ acidified with $\mathrm{HCl}$ (DimitrovsKA et al., 2011). The obtained extracts were filtered through $0.45 \mu \mathrm{m}$ syringe filter and injected into the chromatography system. Three replicates were performed for each cultivar and the obtained extracts were analysed in duplicate.

\subsection{HPLC analysis of anthocyanins}

HPLC analyses were performed on a Shimadzu Prominence LC system, equipped with quaternary pump LC-20AT, photodiode detector SPD-M20A, column oven CTO-20AC and auto sampler SIL-20AC. Chromatography column Purospher®STAR RP-18e supplied from Merck, Darmstadt, Germany ( $250 \mathrm{~mm} \times 4 \mathrm{~mm}$ I.D, $5 \mu \mathrm{m}$ particle size) protected with a guard column of the same packing material ( $4 \mathrm{~mm} \times 4 \mathrm{~mm}$ ) was used for separation of the compounds. The chromatographic conditions were according to Gómez-MígueZ and co-workers (2007). The anthocyanin compounds were identified by their retention time, elution order, and spectral characteristics. The concentration of the compounds identified in the samples was expressed as malvidin-3-glucoside equivalents.

\subsection{Statistical analysis}

Statistical analyses were performed using Microsoft Excel ${ }^{\circledR} 2003$ and SPSS $^{\circledR} 18.0$ software. Analysis of variance was used to assess the difference in the anthocyanin pattern of the skins and young wines of different age obtained with different oenological protocols. In addition, Tukey's post-hoc test with $95 \%$ significance level $(\mathrm{P}<0.05)$ was performed to compare the means.

\section{Results and discussion}

\subsection{Evolution of individual anthocyanins during maceration}

Merlot and Pinot Noir are grape varieties characterised by a distinctive anthocyanin profile and total content of anthocyanins (DimitrovsKa et al., 2011). Pinot Noir is characterised by a lower anthocyanin content compared to other common red grape cultivars (JACKSON, 2000), which was confirmed by our investigation, as well (Table 1). Considering that many different technological approaches are used during winemaking, our intention was to investigate and compare the dynamics of extraction of individual anthocyanins and their behaviour during 
maceration of Merlot and Pinot Noir grape processed with two different vinification procedures.

Table 1. Anthocyanin content in fresh skins and grapes of Merlot and Pinot Noir variety used for wine elaboration ${ }^{\mathrm{a}}$

\begin{tabular}{lccccc}
\hline Anthocyanins & \multicolumn{2}{c}{ Merlot } & & \multicolumn{2}{c}{ Pinot Noir } \\
\cline { 2 - 3 } \cline { 5 - 6 } & $\mu \mathrm{g} / \mathrm{g}$ skins & $\mathrm{mg} / \mathrm{kg}$ grape & & $\mu \mathrm{g} / \mathrm{g}$ skins & $\mathrm{mg} / \mathrm{kg}$ grape \\
\hline De-3-gl & $679.6 \pm 90.1$ & $65.0 \pm 8.6$ & & $114.5 \pm 10.5$ & $9.3 \pm 0.8$ \\
Cy-3-gl & $137.8 \pm 41.5$ & $13.2 \pm 4.0$ & & $58.9 \pm 3.0$ & $4.8 \pm 0.2$ \\
Pt-3-gl & $573.2 \pm 57.3$ & $54.9 \pm 5.5$ & & $165.4 \pm 13.2$ & $13.4 \pm 1.1$ \\
Pn-3-gl & $338.8 \pm 66.0$ & $32.4 \pm 6.3$ & & $691.5 \pm 42.7$ & $56.2 \pm 3.5$ \\
Mv-3-gl & $2670.2 \pm 150.5$ & $255.6 \pm 14.4$ & & $2101.4 \pm 187.2$ & $170.9 \pm 15.2$ \\
De-ac & $149.3 \pm 14.1$ & $14.3 \pm 1.3$ & & & \\
Cy-ac & $54.2 \pm 5.0$ & $5.2 \pm 0.5$ & & & \\
Pt-ac & $166.4 \pm 10.7$ & $15.9 \pm 1.0$ & & & \\
Pn-ac & $114.7+9.2$ & $10.0 \pm 0.9$ & & & \\
Mv-ac & $1088.2 \pm 45.0$ & $104.2 \pm 4.3$ & & & \\
De-coum & $95.1 \pm 9.4$ & $9.1 \pm 0.9$ & & & \\
Pt-coum & $110.1 \pm 10.8$ & $10.5 \pm 1.0$ & & & \\
Pn-coum & $112.8 \pm 12.5$ & $10.8 \pm 1.2$ & & \\
Mv-coum & $674.2 \pm 5.8$ & $64.5 \pm 0.6$ & & \\
Monoglucosides & $4399.6 \pm 405.4$ & $421.1 \pm 38.8$ & & \\
Acetates & $1572.8 \pm 84.1$ & $150.5 \pm 8.0$ & & & \\
Coumarates & $992.3 \pm 38.5$ & $95.0 \pm 3.7$ & & & \\
Total anthocyanins & $6964.7 \pm 527.9$ & $666.6 \pm 50.5$ & $3131.7 \pm 256.6$ & \\
\hline
\end{tabular}

${ }^{a}$ : The reported data are means \pm standard deviation $(n=3)$

b: Abbreviations: De-3-gl: delphinidin-3-glucoside; Cy-3-gl: cyanidin-3-glucoside; Pt-3-gl: petunidine-3-glucoside; Pn-3-gl: peonidin-3-glucoside; Mv-3-gl: malvidin-3-glucoside; De-ac: delphinidin-(6-acetyl)-3-glucoside; Cy-ac: cyanidin-(6-acetyl)-3-glucoside; Pt-ac: petunidin-(6-acetyl)-3-glucoside; Pn-ac: peonidin-(6-acetyl)-3-glucoside; Mv-ac: malvidin-(6-acetyl)-3-glucoside; De-coum: delphinidin-(6-coumaroyl)-3-glucoside; Pt-coum: petunidin(6-coumaroyl)-3-glucoside; Pn-coum: peonidin-(6-coumaroyl)-3-glucoside; Mv-coum - malvidin-(6-coumaroyl)3-glucoside

c: n.d. - not detected

A distinct trend of evolution of individual anthocyanins was found during maceration of Merlot grape (fermentation M-1) and Pinot Noir grape (fermentation PN-1), which is shown in Table 2. The highest concentration of total anthocyanins in Merlot: $622.4 \mathrm{mg} \mathrm{l}^{-1}$ was observed on the third day of the fermentation (Table 2), which is almost $95 \%$ extraction of anthocyanins from the original grape (Table 1). After the maximum values were reached, the concentration continually dropped to $395.7 \mathrm{mg} \mathrm{l}^{-1}$, a level measured on day 10 at devatting of the wine. The most dramatic changes occurred between the first and second day of the fermentation, when the concentration of total anthocyanins increased almost 5 times. This phenomenon is a result of the fast disintegration of the grape berry cell walls, which facilitate the anthocyanin transfer from the cell vacuoles into the must. Monoglucosides were the most abundant group accounting for approximately $62 \%$ of all anthocyanins, followed by the acetates $(25 \%)$ and coumaroyl derivatives $(13 \%)$. 
Table 2. Individual anthocyanin concentrations $\left(\mathrm{mg}^{-1}\right)$ in Merlot and Pinot Noir wines during maceration process and in young wines ( 6 months) obtained by M-1 and PN-1 fermentations ${ }^{\mathrm{a}}$

\begin{tabular}{|c|c|c|c|c|c|c|c|}
\hline \multirow{2}{*}{$\begin{array}{l}\text { Anthocya- } \\
\text { nins } \\
\text { Merlot wine } \\
(\mathrm{M}-1)\end{array}$} & \multicolumn{7}{|c|}{ Days } \\
\hline & 1 & 2 & 3 & 4 & 5 & 10 & 180 \\
\hline De-3-gl $1^{b}$ & $7.3 \pm 0.2$ & $29.7 \pm 0.8$ & $31.4 \pm 1.3$ & $34.5 \pm 1.8$ & $25.8 \pm 3.9$ & $22.7 \pm 1.7$ & $19.3 \pm 0.5$ \\
\hline Cy-3-gl & $5.7 \pm 1.7$ & $7.2 \pm 0.9$ & $6.4 \pm 0.6$ & $5.7 \pm 0.8$ & $4.6 \pm 1.3$ & $4.5 \pm 0.8$ & $3.5 \pm 0.0$ \\
\hline Pt-3-gl & $7.1 \pm 1.8$ & $31.7 \pm 1.1$ & $35.2 \pm 4.2$ & $37.5 \pm 0.6$ & $29.0 \pm 3.7$ & $26.3 \pm 1.4$ & $18.4 \pm 1.0$ \\
\hline Pn-3-gl & $17.4 \pm 2.2$ & $35.4 \pm 3.2$ & $31.5 \pm 2.0$ & $29.0 \pm 1.6$ & $22.0 \pm 3.1$ & $21.0 \pm 1.8$ & $13.4 \pm 1.0$ \\
\hline Mv-3-gl & $37.9 \pm 19.2$ & $224.4 \pm 11.6$ & $291.2 \pm 28.3$ & $237.0 \pm 60.3$ & $179.2 \pm 49.9$ & $169.0 \pm 17.6$ & $98.6 \pm 1.3$ \\
\hline De-ac & $2.7 \pm 0.3$ & $10.6 \pm 0.9$ & $11.9 \pm 1.2$ & $12.3 \pm 0.7$ & $9.6 \pm 0.6$ & $9.3 \pm 0.6$ & n.d. ${ }^{\mathrm{c}}$ \\
\hline Сy-ac & $2.3 \pm 0.3$ & $5.2 \pm 0.9$ & $5.8 \pm 1.0$ & $6.9 \pm 1.4$ & $6.0 \pm 0.6$ & $5.6 \pm 0.5$ & n.d. \\
\hline Pt-ac & $3.1 \pm 0.7$ & $11.5 \pm 2.3$ & $12.4 \pm 3.3$ & $13.2 \pm 0.6$ & $10.4 \pm 0.8$ & $10.0 \pm 0.3$ & n.d. \\
\hline Pn-ac & $4.9 \pm 0.6$ & $13.2 \pm 1.1$ & $13.8 \pm 2.6$ & $14.0 \pm 1.0$ & $11.4 \pm 0.2$ & $11.2 \pm 0.8$ & n.d. \\
\hline Mv-ac & $13.1 \pm 7.1$ & $81.7 \pm 11.2$ & $101.7 \pm 7.4$ & $86.0 \pm 10.3$ & $67.6 \pm 15.5$ & $64.0 \pm 7.5$ & $38.9 \pm 0.8$ \\
\hline De-coum & $1.9 \pm 0.0$ & $6.0 \pm 1.6$ & $6.3 \pm 0.7$ & $7.4 \pm 0.2$ & $5.9 \pm 1.0$ & $5.6 \pm 0.5$ & n.d. \\
\hline Pt-coum & $2.0 \pm 0.2$ & $6.7 \pm 0.9$ & $7.4 \pm 1.4$ & $7.6 \pm 0.4$ & $5.9 \pm 1.2$ & $5.5 \pm 0.5$ & n.d. \\
\hline Pn-coum & $2.8 \pm 0.1$ & $14.8 \pm 3.1$ & $13.6 \pm 2.6$ & $12.0 \pm 1.6$ & $9.1 \pm 0.1$ & $8.6 \pm 1.3$ & n.d. \\
\hline Mv-coum & $4.7 \pm 1.5$ & $44.3 \pm 6.2$ & $53.8 \pm 7.1$ & $48.9 \pm 3.8$ & $36.8 \pm 7.9$ & $32.4 \pm 0.5$ & $18.3 \pm 1.7$ \\
\hline $\begin{array}{l}\text { Monogluco- } \\
\text { sides }\end{array}$ & $75.4 \pm 25.1$ & $328.4 \pm 17.6$ & $395.7 \pm 36.4$ & $343.7 \pm 65.1$ & $260.6 \pm 61.9$ & $243.5 \pm 23.3$ & $153.2 \pm 4.8$ \\
\hline Acetates & $26.1 \pm 9.0$ & $122.2 \pm 16.4$ & $145.6 \pm 15.5$ & $132.4 \pm 14.0$ & $105.0 \pm 17.7$ & $100.1 \pm 9.7$ & $38.9 \pm 0.8$ \\
\hline Coumarates & $11.4 \pm 1.8$ & $71.8 \pm 11.8$ & $81.1 \pm 11.8$ & $75.9 \pm 6.0$ & $57.7 \pm 10.2$ & $57.7 \pm 2.8$ & $18.3 \pm 1.7$ \\
\hline Total & $112.9 \pm 35.9$ & $522.4 \pm 45.8$ & $622.4 \pm 63.7$ & $552.0 \pm 85.1$ & $423.3 \pm 89.8$ & $395.7 \pm 35.8$ & $210.4 \pm 6.3$ \\
\hline \multicolumn{8}{|l|}{$\begin{array}{l}\text { P. Noir wine } \\
(\mathrm{PN}-1)\end{array}$} \\
\hline De-3-gl & $0.7 \pm 0.1$ & $1.6 \pm 0.2$ & $2.7 \pm 0.6$ & $4.0 \pm 0.9$ & $5.0 \pm 1.0$ & $5.0 \pm 0.6$ & $3.2 \pm 0.0$ \\
\hline Cy-3-gl & $2.2 \pm 0.6$ & $5.3 \pm 0.8$ & $6.2 \pm 1.9$ & $5.7 \pm 2.4$ & $3.4 \pm 0.6$ & $2.8 \pm 0.1$ & $2.2 \pm 0.4$ \\
\hline Pt-3-gl & $1.0 \pm 1.0$ & $2.5 \pm 0.9$ & $3.8 \pm 1.6$ & $5.5 \pm 1.1$ & $7.1 \pm 1.5$ & $8.3 \pm 1.1$ & $4.3 \pm 0.1$ \\
\hline Pn-3-gl & $14.9 \pm 0.9$ & $30.7 \pm 2.7$ & $39.7 \pm 7.3$ & $42.9 \pm 1.8$ & $30.7 \pm 3.8$ & $20.3 \pm 3.4$ & $10.2 \pm 2.1$ \\
\hline Mv-3-gl & $9.3 \pm 3.6$ & $27.5 \pm 8.8$ & $46.8 \pm 10.8$ & $65.1 \pm 5.1$ & $81.5 \pm 11.5$ & $100.3 \pm 5.8$ & $53.6 \pm 4.5$ \\
\hline Total & $28.1 \pm 6.2$ & $67.6 \pm 13.4$ & $99.2 \pm 22.2$ & $123.2 \pm 11.3$ & $127.7 \pm 18.4$ & $136.7 \pm 10.0$ & $73.5 \pm 7.1$ \\
\hline
\end{tabular}

${ }^{\text {a: }}$ The reported data are means \pm standard deviation of triplicate samples; ${ }^{\text {b }}$ for the abbreviations refer to Table 1 ; c: n.d.: not detected

After 6 months of aging, the total amount of anthocyanins in the wine decreased to $210.4 \mathrm{mg} \mathrm{l}^{-1}$, which is almost half of the original quantity at the end of fermentation. Some of the acylated anthocyanin forms were not detected in the aged wine. This was assumed to be a result of condensation and polymerisation reactions they undergo during the maturation 
period. Despite the decreased concentration of the total amount of anthocyanins during the fermentation, there was no striking change of the fingerprint, except for the wines aged 180 days. These findings are similar to those reported by REVILLA and co-workers (2005), that the length of storage affected the anthocyanin fingerprint of Tempranillo wines, but the technological factors and the storage container had negligible influence.

The rate of extraction of the anthocyanins during vinification of Pinot Noir was slightly slower compared to Merlot (Table 2). Maximum concentration values of the total anthocyanins were obtained on day 10 of fermentation, reaching $136.7 \mathrm{mg} \mathrm{l}^{-1}$, which is about $54 \%$ extraction of the anthocyanins determined in the original grape (Table 1). However, during the winemaking processes not all anthocyanin compounds were extracted following the same dynamics. Namely, while most of the anthocyanins attained the highest concentration values on day 10, peonidin-3-glucoside (Pn-3-gl) and cyanidin-3-glucoside (Cy-3-gl) reached their concentration peak on day 4 and 5 of maceration, respectively. The major compound was malvidin-3-glucoside (Mv-3-gl), followed by peonidin-3-glucoside. The other monoglucosides were less abundant, with concentrations lower than $10 \mathrm{mg} \mathrm{l}^{-1}$ per compound. After 6 months maturation of the wine, the concentration of total anthocyanins decreased to $73.5 \mathrm{mg} \mathrm{l}^{-1}$, which is approximately half of the maximum concentration.

\subsection{Anthocyanin pattern of grapes vs. corresponding wines}

The debate about the similarity of the anthocyanin patterns of grapes and corresponding wines is still present. Some authors (Romero-Cascales et al., 2005; Moreno-Aribas et al., 2008) found that the fingerprint of grapes was different from the one of the elaborated wines, and influenced by the technology applied in their winemaking. On the other hand, others (GAMBACORTA et al., 2011; PuÉRTOLAS et al., 2011) reported that extraction of phenolics from grape skins to wine was mostly depending on the grape variety rather than on the applied winemaking technology. Nevertheless, if some correlation between the grape and wine anthocyanin patterns could be confirmed, it may be used for authentication purposes and controlling the origin of the wine. For better understanding of this issue, anthocyanin composition of the grape skins, wine after devatting, and young wine obtained from Merlot and Pinot Noir grapes by two different vinification protocols were determined and the results are presented in Table 3. No significant differences in the relative amounts were found for most of the anthocyanin compounds monitored in wines of identical age (10 days and 180 days), when comparing fermentations M-1 and M-2. It was observed, that addition of different types of oenological aids (macerating enzymes, tannins, chips) and different yeast strains, while keeping the same operation protocols (type of maceration, fermentation temperature, devatting, etc.) for each fermentation, did not influence the anthocyanin pattern of the wine. BAUTISTA-ORTíN and co-workers (2007) investigated the influence of the yeast culture on the colour of Monastrel wines, and reported non-consistent effects using the same yeasts in two consecutive vintages.

Statistically significant differences were observed in the relative content of almost all anthocyanins detected in wines obtained by the same fermentation but of different age ( 9 and 180 days). This fact confirms, that during aging, anthocyanins undergo transformations such as degradation, polymerization, and adsorption to the yeast cell walls that influence the change of the anthocyanin composition of wine. Comparing the data of the grapes and the respective wines, it was noted that their fingerprints differed significantly, which coincides with other published results (Revilla et al., 2001; González-Neves et al., 2002). 


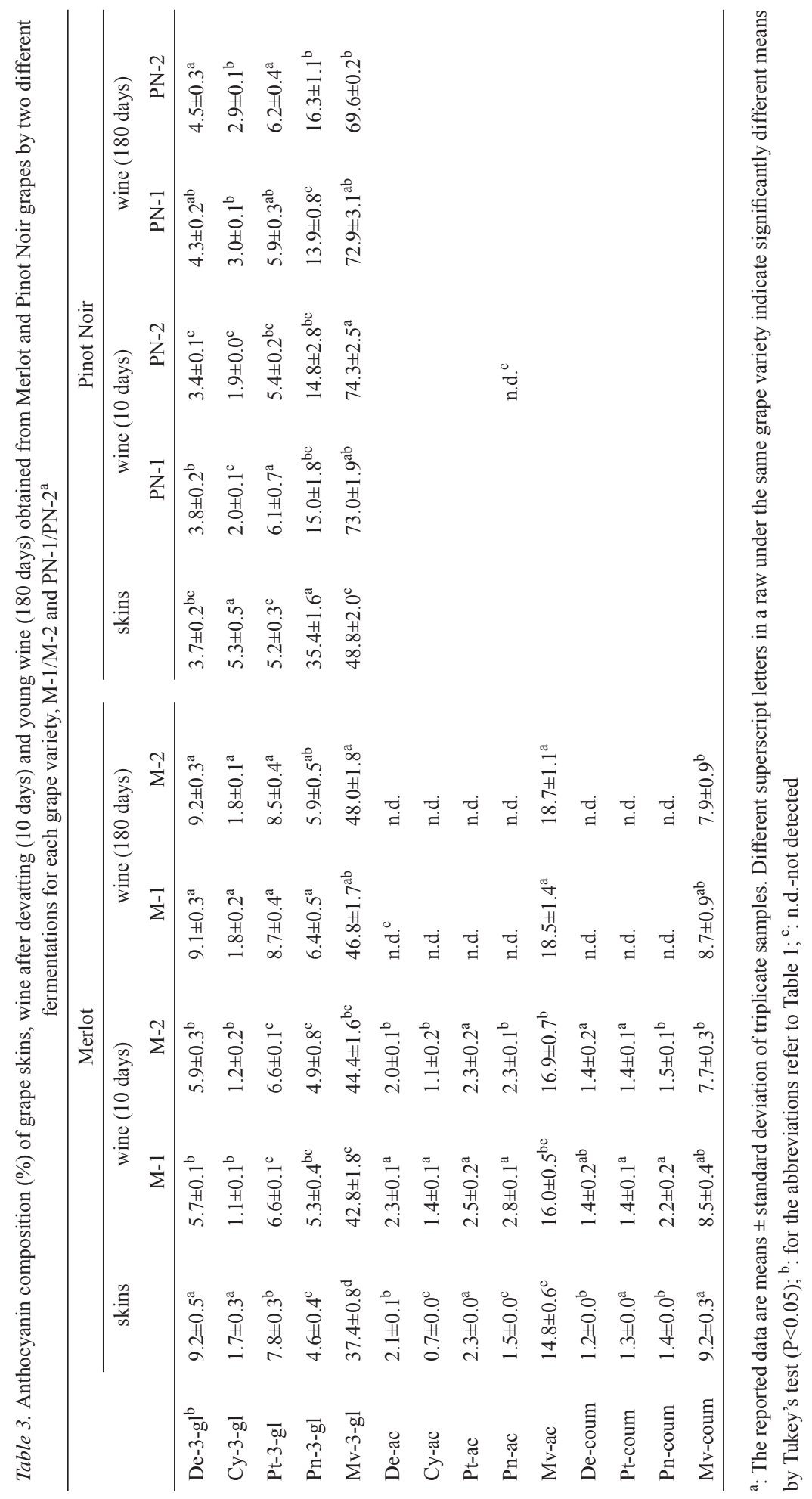


The anthocyanin pattern of the older wines (180 days) was more similar to the original grapes, particularly in the proportions of delphinidin-3-glucoside, petunidin-3-glucoside, and cyanidin-3-glucoside. The proportions of malvidin-3-glucoside and malvidin acetate were higher in wines than in the grape skins, which was not the case for malvidin coumarate.

Very similar observations were established comparing the anthocyanin composition of Pinot Noir grapes and wines (Table 3). No significant difference concerning the anthocyanin pattern was noticed for the wines of the same age. Moreover, during ageing of Pinot Noir (180 days), no significant changes occurred in the anthocyanin composition of the wine, which could possibly be related to the absence of acylated anthocyanin compounds in this grape variety. In the case of Pinot Noir, the differences between the anthocyanin composition of skins and wine were more evident. This finding suggests that alcoholic fermentation alters the anthocyanin fingerprint of the obtained wines, but the addition of oak chips had a negligible effect.

The relative content of malvidin-3-glucoside in Merlot and especially in Pinot Noir was significantly higher in wines than in grape skins. GARCÍA-BENEYTEZ and co-workers (2002) reported significant drop of the peonidin-3-glycoside relative content from fresh grapes to wines for some varieties. In our study this was confirmed only for Pinot Noir wines, but not for Merlot wines. The same authors found lower relative content of coumaroylated derivatives in wines than in grape skins. In our work this was confirmed only for malvidin coumarate in Merlot wines after 10 days fermentation. The other coumaroyl compounds in these wines (10 days) were almost equal or slightly higher than in grape skins. In the young wines of 180 days age, malvidin coumarate was the only coumaroyl compound detected.

Several authors have investigated Pinot Noir, emphasizing the distinct anthocyanin pattern of this variety (MAZZA et al., 1999; CoRTell et al., 2007; He et al., 2012). The absence of acylated anthocyanins as a chemotaxonomic marker for Pinot Noir related to the genes expression (DAI et al., 2011) was confirmed in grapes and wines by all previously mentioned authors. The results of the anthocyanin pattern of Pinot Noir grapes and wines from the region of Macedonia obtained in this study support the thesis of Pinot Noir authenticity, confirming that they do not differ from the worldwide grapes and wines of the same variety.

\section{Conclusions}

The results confirmed that the anthocyanin composition of the grape skins differs from that of the obtained respective wines for both studied varieties, Merlot and Pinot Noir. On the other hand, the anthocyanin patterns of the wines of the same age obtained from one variety but with different vinification protocols were similar. The differences between the anthocyanin composition of the grape skins and respective wines, caused during vinification, seemed to be cultivar related. These findings could be promising for establishing certain relationship between the anthocyanin pattern of the grape skins and corresponding wines that could be used for authentication purposes. More significant changes of the composition of anthocyanins were observed over time, during wine aging, which suggests that the age of the wine could be a restrictive factor in assessment of authenticity related to the anthocyanin fingerprint. 


\section{References}

Arozarena, I., Casp, A., Marín, R. \& Navarro, M. (2000): Multivariate differentiation of Spanish red wines according to region and variety. J. Sci. Food Agric., 80, 1909-1917.

Bautista-Ortín, A.B., Romero-Cascales, I., Fernández-Fernández, J.I., López-Roca, J.M. \& Gómez-Plaza, E. (2007): Influence of the yeast strain on Monastrell wine colour. Innov. Food Sci. Emerg., 8, 322-328.

Casavecchia, C., Magnisi, R., La Pera, L., Maisano, R. \& Dugo, G. (2007): Classification of Sicilian red wines from autochthonous and allochthonous cultivars according to anthocyanin pattern. Am. J. Enol. Viticult., 58, 286290.

Cortell, J.M., Halbleib, M., Gallagher, A.V., Righetti, T.L. \& Kennedy, J.A. (2007): Influence of vine vigor on grape (Vitis vinifera L. Cv. Pinot Noir) anthocyanins. Anthocyanins and pigmented polymers in wine, J. Agr. Food Chem., 55, 6585-6595.

Dai, Z.W., Ollat, N., Gomès, E., Decroocq, S., Tandonnet, J., Bordenave, L., Pieri, P., Hilbert, G., Kappel, C., van Leeuwen, C., Vivin, P. \& Delrot, S. (2011): Ecophysiological, genetic, and molecular causes of variation in grape berry weight and composition: A review. Am. J. Enol. Viticult., 62, 413-425.

Dimitrovska, M., Bocevska, M., Dimitrovski, D. \& Murkovic, M. (2011): Anthocyanin composition of Vranec, Cabernet Sauvignon, Merlot and Pinot Noir as indicator of their varietal differences. Eur. Food Res. Technol., 232, 591-600.

Gambacorta, G., Antonacci, D., Pati, S., La Gatta, M., Faccia, M., Coletta, A. \& La Notte, E. (2011): Influence of winemaking technologies on phenolic composition of Italian red wines. Eur. Food Res. Technol., 233, 1057-1066.

García-Beneytez, E., Revilla, E. \& Cabello, F. (2002): Anthocyanin pattern of several red cultivars and wines made from them. Eur. Food Res. Technol., 215, 32-37.

Gómez-Míguez, M., GonzÁlez-Miret, L.M. \& Heredia, F.J. (2007): Evolution of colour and anthocyanin composition of Syrah wines elaborated with pre-fermentative cold maceration. J. Food Eng., 79, 271-278.

Gómez-Plaza, E., Gil-Muñoz, R., López-Roca, J.M., Martínez-Cutillas, A. \& Fernández-Fernández, J.I. (2002): Maintenance of colour composition of a red wine during storage. Influence of prefermentative practices, maceration time and storage. LWT-Food Sci. Technol., 35, 46-53.

GonzÁlez-Neves, G., Gil, G. \& Ferrer, M. (2002): Effect of different vineyard treatments on the phenolic contents in Tannat (Vitis vinifera L.) grapes and their respective wines. Food Sci. Technol. Int., 8, 315-321.

He, F., Liang, N., Pan, Q., Wang, J., Reeves, M. \& Duan, C. (2012): Anthocyanins and their variation in red wines II. Anthocyanin derived pigments and their colour evolution. Molecules, 17, 1483-1519.

JACKSON, S.R. (2000): Wine science: Principles, practice, perception. Academic Press, New York, USA, pp. 242250.

Keleber, H., Canbas, A., Cabaroglu, T. \& Selli, S. (2007): Improvement of anthocyanin content in the cv. Öküzgözü wines by using pectolytic enzymes. Food Chem., 105, 334-339.

Mazza, G., Fukumoto, L., Delaquis, P., Girard, B. \& Ewert, B. (1999): Anthocyanins, phenolics and color of Cabernet Franc, Merlot and Pinot Noir wines from British Columbia. J. Agr. Food Chem., 47, 4009-4017.

Moreno-Aribas, M.V., Gómez-Cordovés, C. \& Martín-Álvarez, P.J. (2008): Evolution of red wine anthocyanins during malolactic fermentation, postfermentative treatments and aging with lees. Food Chem., 109, 149-158.

Puértolas, E., Álvarez, I. \& Raso, J. (2011): Changes in phenolic compounds of Aragón red wines during alcoholic fermentation. Food Sci. Technol. Int., 17, 77-86.

Revilla, E., García-Beneytez, E., Cabello, F., Martín-Ortega, G. \& Ryan, J.M. (2001): Value of high performance liquid chromatographic analysis of anthocyanins in the differentiation of red grape cultivars and red wines made from them. J. Chromatogr. A., 915, 53-60.

Revilla, E., LóPEZ, J.F. \& RyAn, J.M. (2005): Anthocyanin pattern of Tempranillo wines during ageing in oak barrels and storage in stainless-steel tanks. Eur. Food Res. Technol., 220, 592-596.

Romero-Cascales, I., Fernández-Fernández, J.I., López-Roca, J.M. \& Gómez-Plaza, E. (2005): The maceration process during winemaking extraction of anthocyanins from grape skins into wine. Eur. Food Res. Technol., $221,163-167$. 